\title{
Further genetic characterization of the two Trypanosoma cruzi Berenice strains (Be-62 and Be-78) isolated from the first human case of Chagas disease (Chagas, 1909)
}

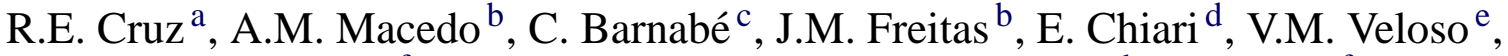 \\ C.M. Carneiro ${ }^{\mathrm{a}, \mathrm{f}}$, M.T. Bahia ${ }^{\mathrm{a}, \mathrm{e}}$, Washington L Tafuri ${ }^{\mathrm{a}, \mathrm{d}}$, M. Lana ${ }^{\mathrm{a}, \mathrm{f}, *}$ \\ a Núcleo de Pesquisas em Ciências Biológicas (NUPEB), Instituto de Ciências Exatas e Biológicas (ICEB), UFOP, Brazil \\ ${ }^{\mathrm{b}}$ Departamento de Bioquímica e Imunologia, Instituto de Ciências Biológicas (ICB), Universidade Federal de \\ Minas Gerais (UFMG), Belo Horizonte, MG, Brazil \\ ${ }^{\mathrm{c}}$ Génétique des Maladies infectieuses, Unité Mixte de Recherche Centre National de la Recherche Scientifique (CNRS)/Institut de \\ Recherche pour le Développement (IRD) no 9926, IRD, BP 64501, 34394 Montpellier Cedex 05, France \\ ${ }^{\mathrm{d}}$ Departamento de Parasitologia, ICB, UFMG, Brazil \\ e Departamento de Ciências Biológicas, ICEB, UFOP, Brazil \\ ${ }^{\mathrm{f}}$ Departamento de Análises Clínicas, Escola de Farmácia, Universidade Federal de Ouro Preto, Rua Costa Sena, 171, \\ CEP 35 400-000 Ouro Preto, MG, Brazil
}

Received 15 June 2004; received in revised form 9 November 2004; accepted 8 March 2005

Available online 15 December 2005

\begin{abstract}
We describe here an extension of a previous genetic characterization of Trypanosoma cruzi strains (Be-62 and Be-78) isolated from the patient Berenice, the first human case of Chagas disease [Chagas, C., 1909. Nova Tripanomíase humana. Estudos sobre morfologia e o ciclo evolutivo do Schizotrypanum cruzi, n. gen., n. sp., agente etiolójico da nova entidade morbida do homem. Mem. Inst. Oswaldo Cruz 1, 159-218]. We wanted to verify the composition of T. cruzi populations originated from these two isolates. In the present work, 22 enzymatic loci (MLEE), nine RAPD primers and 7 microsatellite loci were analyzed. Clones from both strains were also characterized to verify whether these strains are mono or polyclonal. Be-62 and Be-78 strains were different in 3 out of 22 enzymatic systems, in 3 out of 9 RAPD primers tested and in all microsatellite loci investigated. However, our data suggests that both strains are phylogenetically closely related, belonging to genetic group 32 from Tibayrenc and Ayala [Tibayrenc, M., Ayala, F.J., 1988. Isoenzime variability in Trypanosoma cruzi, the agent of Chagas' disease: genetical, taxonomical, and epidemiological significance. Evolution 42, 277-292], equivalent to zymodeme 2 and T. cruzi II major lineage which, in Brazil, comprises parasites from the domestic cycle of the disease. Microsatellite analyses showed differences between
\end{abstract}

\footnotetext{
* Corresponding author. Tel.: +55 31 35591680; fax: +55 3135591680 .

E-mail address: delana@nupeb.ufop.br (M. Lana).
} 
the parental strains but suggested that both populations are monoclonal since each strain and their respective clones showed the same amplification products.

(C) 2005 Published by Elsevier B.V.

Keywords: Trypanosoma cruzi; Berenice strains; Isoenzyme; RAPD; Microssatellites

\section{Introduction}

Chagas disease is a very important tropical disease in South America caused by Trypanosoma cruzi. The first human case of was discovered by Chagas (1909) when he examined a 2-year-old girl, named Berenice, in Lassance, Minas Gerais state, Brazil. Two strains of T. cruzi isolated from this patient in 1962 and 1978 and further named Be-62 (Salgado et al., 1962) and Be-78 (Lana and Chiari, 1986) were comparatively studied revealing several important differences. Be78 showed to be different from Be-62 in relation to morphology, parasitemia, tissue tropism, pathogenicity, mortality in mice, growth and differentiation in LIT media (Lana and Chiari, 1986) and izoenzyme and kDNA profiles (Lana et al., 1996). Furthermore, contrasting with Be-62 infections, mice and dogs infected with Be-78 develop intense cardiac lesions and fibrosis reproducing experimentally the characteristics of the human chagasic cardiopathy (Lana and Chiari, 1986; Lana et al., 1992; Araújo et al., 2002). However, from the molecular point of view, especially in relation to nuclear genome, these strains had been poorly studied. To further investigate the population structure of Berenice strains we extended the initial biochemical and genetic characterization of them by using extra enzymatic loci (MLEE-multilocus enzyme electrophoresis), randomly amplified polymorphic DNA (RAPD), and microsatellite analyses. In addition, laboratory clones derived from both strains were also characterized.

\section{Material and methods}

\subsection{T. cruzi strains and clones}

Be-62 (Salgado et al., 1962) and Be-78 (Lana and Chiari, 1986) strains were isolated by xenodiagnosis from Berenice patient and maintained by successive blood passages in mice. For this study parasites were isolated from mice through hemoculture, cultivated in LIT medium and clones were obtained by successive dilutions according to Gomes et al. (1991).

The parental strains (Be-62 and Be-78) and their respective clones (Be-62cl3, Be-62cl7, Be-62cl8 and $\mathrm{Be}-62 \mathrm{cl} 12)$ and $(\mathrm{Be}-78 \mathrm{cl} 2, \mathrm{Be}-78 \mathrm{cl}$, Be-78cl10 and $\mathrm{Be}-78 \mathrm{cl15}$ ) were characterized. We also analyzed, as a reference, $T$. cruzi clones from the main natural genetic groups or clonets (Tibayrenc and Ayala, 1988) including SilvioX10cl1 (19-20), CANIIIcl1 (27), MAS1cl1 (32), MNcl2 (39), M6241cl5 (36) and TULAcl2 (43).

\subsection{Multiloci enzyme electrophoresis (MLEE) analyses}

For isoenzyme analyses a volume of approximately $80 \mathrm{ml}$ of parasites in exponential growth phase in LIT medium was used. Flagellates were washed twice with phosphate buffer solution (PBS) by centrifugation at $3500 \mathrm{rpm}, 4^{\circ} \mathrm{C}$, and the pellet stored at $-70^{\circ} \mathrm{C}$ until use. Enzymatic extracts were prepared according to Kilgour and Godfrey (1973) and cryopreserved in liquid nitrogen.

The enzymatic extracts were analyzed in cellulose acetate plates according to Ben Abderrazak et al. (1993). Twenty enzymes were studied: aconitase (E.C. 4.2.1.3, ACON), alanine aminotransferase (E.C. 2.6.1.2, ALAT), diaphorase (E.C. 1.6.99.2, DIA), glyceraldehyde-3-phosphate dehydrogenase (E.C. 1.2.1.12, GAPD), glutamate dehydrogenase NAD+ (E.C. 1.4.1.2, GDH-NAD+), glutamate dehydrogenase NADP+ (E.C. 1.4.1.4, GDH-NADP+), aspartate amino transferase (E.C. 2.6.1.1, GOT), glucose-6-phosphate dehydrogenase (E.C. 1.1.1.49, G6PD), glucose-6-phosphate isomerase (E.C. 5.3.1.9, GPI), isocitrate dehydrogenase (E.C. 1.1.1.42, IDH), leucine aminopeptidase (cytosol aminopeptidase) (E.C. 3.4.11.1, LAP), malate dehydrogenase (E.C. 1.1.1.37, $\mathrm{MDH}$ ), malate dehydrogenase (oxaloacetate decarboxylating, NADP+) or malic enzyme (E.C. 
1.1.1.40, ME), mannose-phosphate isomerase (E.C. 5.3.1.8, MPI), nucleoside hydrolase (E.C. 2.4.2.1, NHi); substrate: inosine, peptidase 1 (E.C. 3.4.22.3, formerly E.C. 3.4.4.12, PEP-1); substrate: leucylleucyl-leucine, peptidase 2 (E.C. 3.4.22.4, formerly E.C. 3.4.4.24, PEP-2; substrate: leucyl-L-alanine), 6phosphoglucomutase dehydrogenase (E.C. 1.1.1.44, 6PGD), phosphoglucomutase (E.C. 5.4.2.2, formerly E.C. 2.7.5.1, PGM), and superoxide dismutase (E.C. 1.15.1.1, SOD).

\subsection{RAPD analysis}

DNA extractions were performed from the pellets remaining after the enzymatic extraction, according to Brisse et al. (2000). Each RAPD reaction was performed in a total volume of $60 \mu \mathrm{l}$ of $1 \times \mathrm{Mg}$-free buffer; containing 0.9 U Taq DNA polymerase (GIBCO, Invitrogen); $0.1 \mathrm{mM}$ dNTP mixture (Pharmacia Biotec); $1.5 \mathrm{mM} \mathrm{MgCl} 2 ; 0.2 \mu \mathrm{M}$ of each primer and $20 \mathrm{ng}$ of the DNA template. Twenty microlitres of mineral oil was added to the mixture to avoid evaporation of the reagents. Primers F13 (5'-GGCTGCAGAA- $\left.3^{\prime}\right)$, B15 (5'-GGAGGGTGTT-3'), N19 (5'-GTCCGTACTG$\left.3^{\prime}\right)$, A10 (5'-GTGATCGCAG-3'), F15 (5'-CCAGTACTCC- $\left.3^{\prime}\right)$, N9 $\left(5^{\prime}\right.$-TGCCGGCTTG- $\left.3^{\prime}\right)$, A15 (5'TTCCGAACCC- $\left.3^{\prime}\right)$, U7 (5'-CCTGCTCATC-3') and B19 (5'-ACCCCCGAAG-3 $\left.{ }^{\prime}\right)$ from Operon Technologies, Alameda California, CA, USA, were used.

The amplification program comprised 45 cycles: initial denaturation step at $94^{\circ} \mathrm{C}$ for $1 \mathrm{~min}$, annealing at $36^{\circ} \mathrm{C}$ for $1 \mathrm{~min}$; extension at $72^{\circ} \mathrm{C}$ for $2 \mathrm{~min}$, followed by a final extension step at $72^{\circ} \mathrm{C}$ for $7 \mathrm{~min}$.

Electrophoresis was performed in $1 \%$ agarose gels at $100 \mathrm{~V}$. Products were stained by ethidium bromide and visualized under UV light.

\subsection{Microsatellite analyses}

Microsatellite analyses were performed with DNA obtained from the parental strains and their clones cultivated in LIT medium. T. cruzi stocks were analyzed with the SCLE10 (5'-GATCCCGCAATAGGAAAC$3^{\prime}$ and $5^{\prime}$-GTGCATGTTCCATGGCTT- $3^{\prime}$ ), MCLE01 (5'-CTGCCATGTTTGATCCCT-3' and 5' ${ }^{\prime}$-CGTGTACATATCGGCAGTG-3'), MCLG10 (5'-AGGAGTCAAATATAATGAGGCA-3' and 5'-ACGTGTGAAA-
GGCATCTATC-3') loci described by Oliveira et al. (1998) and TcTAC-02 (5'-GAATTTCCCCATTTCCAAGC- $3^{\prime}$ and $5^{\prime}$-CGATGAGCAACAATCGCTTC$\left.3^{\prime}\right)$ TcAAT-01 (5'-ACCTCATCGGTGTGCATGTC-3' and $5^{\prime}$-GTCGCCGTGCAATTTC- $\left.3^{\prime}\right)$, TcTAT-01 (5'GATCCTTGAGCAGCCACCAA-3' and 5'-CAAATTCCCAACGCAGCAGC- $\left.3^{\prime}\right)$, TcAAAT-01(5'-GCCGTGTCCTAAAGAGCAAG-3' and 5'-GGTTTTAGGGCCTTTAGGTG-3') loci kindly provided by Dr. Juliana Pimenta. Amplification was performed basically as described by Oliveira et al. (1998). Each reaction was performed in a total volume of $15 \mu \mathrm{l}$ containing 0.75 U Taq DNA polymerase (Phoneutria), $2.5 \mathrm{mM}$ each dNTP and $0.05 \mu \mathrm{M}$ each primer. The reaction buffer consisted of $100 \mathrm{mM}$ Tris- $\mathrm{HCl}(\mathrm{pH} 8.8), 35 \mathrm{mM}$ $\mathrm{MgCl}_{2}, 250 \mathrm{mM} \mathrm{KCl}$ and $3 \mu \mathrm{l}$ DA template $(1 \mathrm{ng} / \mu \mathrm{l})$ covered with $20 \mu \mathrm{l}$ mineral oil: distribution of the mixtures and mineral oil was performed by an automatic BIOMEC 2000 robot. Amplification was performed in a PT100 thermocycler (MJ Research) using the step-down protocol (Hecker and Roux, 1996) modified for amplification of $T$. cruzi DNA: initial denaturation step at $94{ }^{\circ} \mathrm{C}$ for $5 \mathrm{~min}$, annealing at $58^{\circ} \mathrm{C}$ for $30 \mathrm{~s}$; extension at $72{ }^{\circ} \mathrm{C}$ for $30 \mathrm{~s}$ and denaturation step at $94^{\circ} \mathrm{C}$ for $30 \mathrm{~s}$. At each five cycles, the temperature of annealing was decreased by $2^{\circ} \mathrm{C}$ down to $48^{\circ} \mathrm{C}$. At this temperature the number of cycles increased to 10 , followed by a final extension step at $72{ }^{\circ} \mathrm{C}$ for $7 \mathrm{~min}$. The microsatellite amplicons were loaded on a $6 \%$ denaturing polyacrylamide gel and analyzed in an ALF sequencer (Pharmacia) using the Allelinks software.

\subsection{Phylogenetic analysis}

To estimate the genetic divergence among the stocks, Jaccard's genetic dissimilarity index was used (Jaccard, 1908). It measures the proportion of band mismatches between a pair of stocks according to the following formula: $D=1-(a /(a+b+c))$, where $a=$ number of bands that are common to the two compared genotypes, $b=$ number of bands present in the first genotype and absent in the second and $c=$ number of bands absent in the first genotype and present in the second. The unweighted pair group method with arithmetic averages method (UPGMA) (Sneath and Sokal, 1973) was used to construct phylogenetic trees based on these distances. Different softwares were 
used: "Genetics" (unpublished) to compute distances, "Neighbor" from the package PHYLIP (Felsenstein, 1989) to manage UPGMA protocols and "Treeview" to display the trees (Page, 1996).

\section{Results}

\subsection{MLEE patterns of Be-62 and Be-78 strains}

We analyzed 22 enzymatic loci of the Be-62 and Be-78 T. cruzi strains (Table 1). From these, only DIA-NADH and PGM enzymes showed slight differences between both strains. Be-62 and Be-78 strains were very similar to each other and also with clone MAScl1, used as a reference genotype. Both differed from MAScl1 in relation to DIA-NADH, but only Be78 strain differed from MAScl1 in relation to PGM. Fig. 1 shows a representative result obtained with PGM.

\subsection{RAPD patterns of Be-62 and Be-78 strains}

Nine primers were used in an attempt to differentiate the Be-62 and Be-78 strains. Only three out of tested
Table 1

Comparative MLLE profiles between Be-62 of and Be-78 Trypanosoma cruzi strains

\begin{tabular}{lll}
\hline Enzymes & \multicolumn{2}{l}{ T. cruzi strains and MLEE profiles } \\
\cline { 2 - 3 } & Be-62 & Be-78 \\
\hline GPI & 3 & 3 \\
MDH & 6 & 6 \\
ME1 & 3 & 3 \\
ME2 & 4 & 4 \\
DIANADH & $\mathbf{3}$ & $\mathbf{5}$ \\
DIANADPH & 4 & 4 \\
6PG & $6-7$ & $6-7$ \\
PEP1 & $3-5$ & $3-5$ \\
PEP2 & 2 & 2 \\
Nhi & 1 & 1 \\
GCH1 & 5 & 5 \\
GDH2 & 4 & 4 \\
GOT & 4 & 4 \\
MPI & 1 & 1 \\
GAPD & 6 & 6 \\
PGM & $\mathbf{9 - 1 1}$ & $\mathbf{8 - 1 1}$ \\
ALAT & 3 & 3 \\
LAP & 4 & 4 \\
G6PD & 2 & 2 \\
IDH & $5-6$ & $5-6$ \\
SOD & $6-7$ & $6-7$ \\
ACON & $9-9$ & $9-9$ \\
\hline
\end{tabular}

Numbers indicate the relative position of bands in the electrophoresis gels. Bold faces indicate the enzymes with different electrophoresis mobility between Be-68 and Be-72.

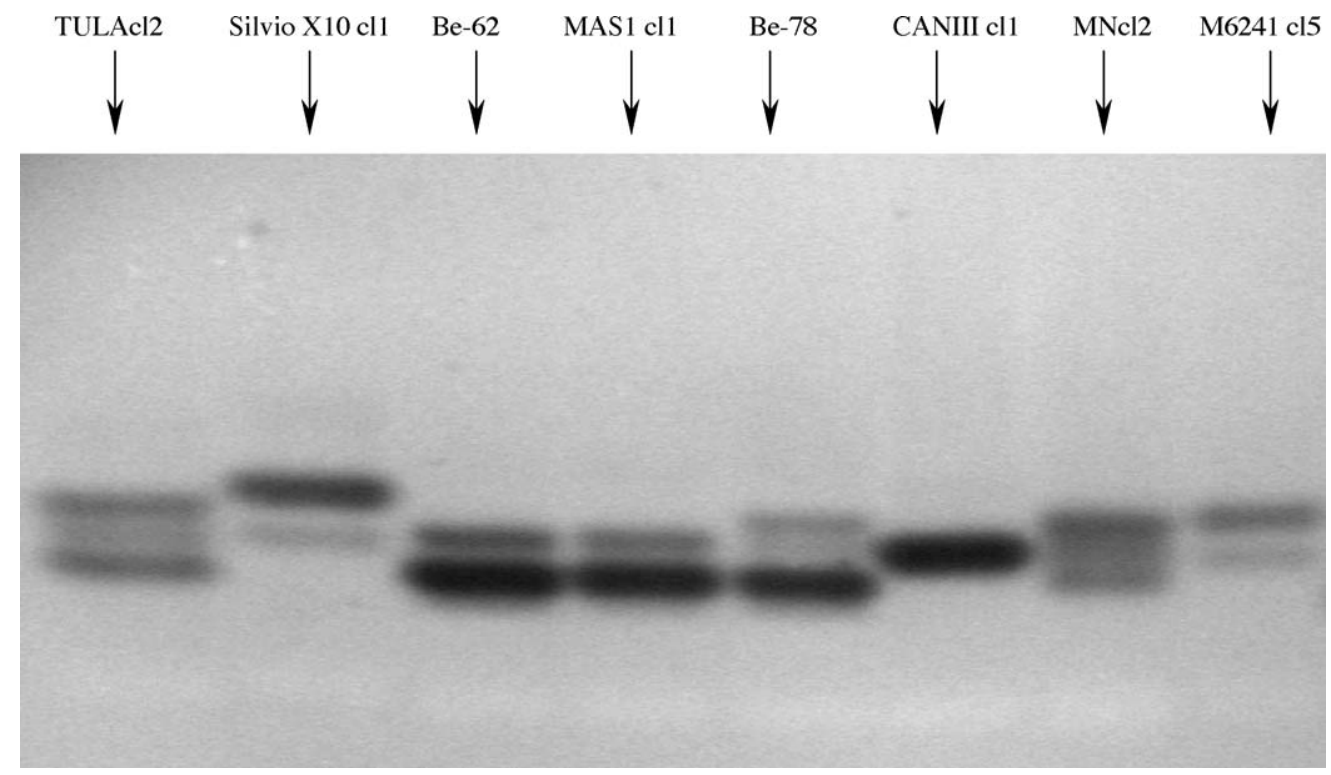

Fig. 1. Isoenzyme patterns of PGM are showing differences between the Be-62 and Be-78 strains and similarity of both with the clone MAScl1 belonging to the genotype 32 of Trypanosoma cruzi. The sequence of the stocks assayed was: TULAcl2 (genotype 43), SilvioX10cl1 (genotype 19 and 20), Be-62 strain, MAS1cl1 (genotype 32), Be-78 strain, CANIIIcl1 (genotype 27), MNcl2 (genotype 39) and M6241cl5 (genotype 36). 

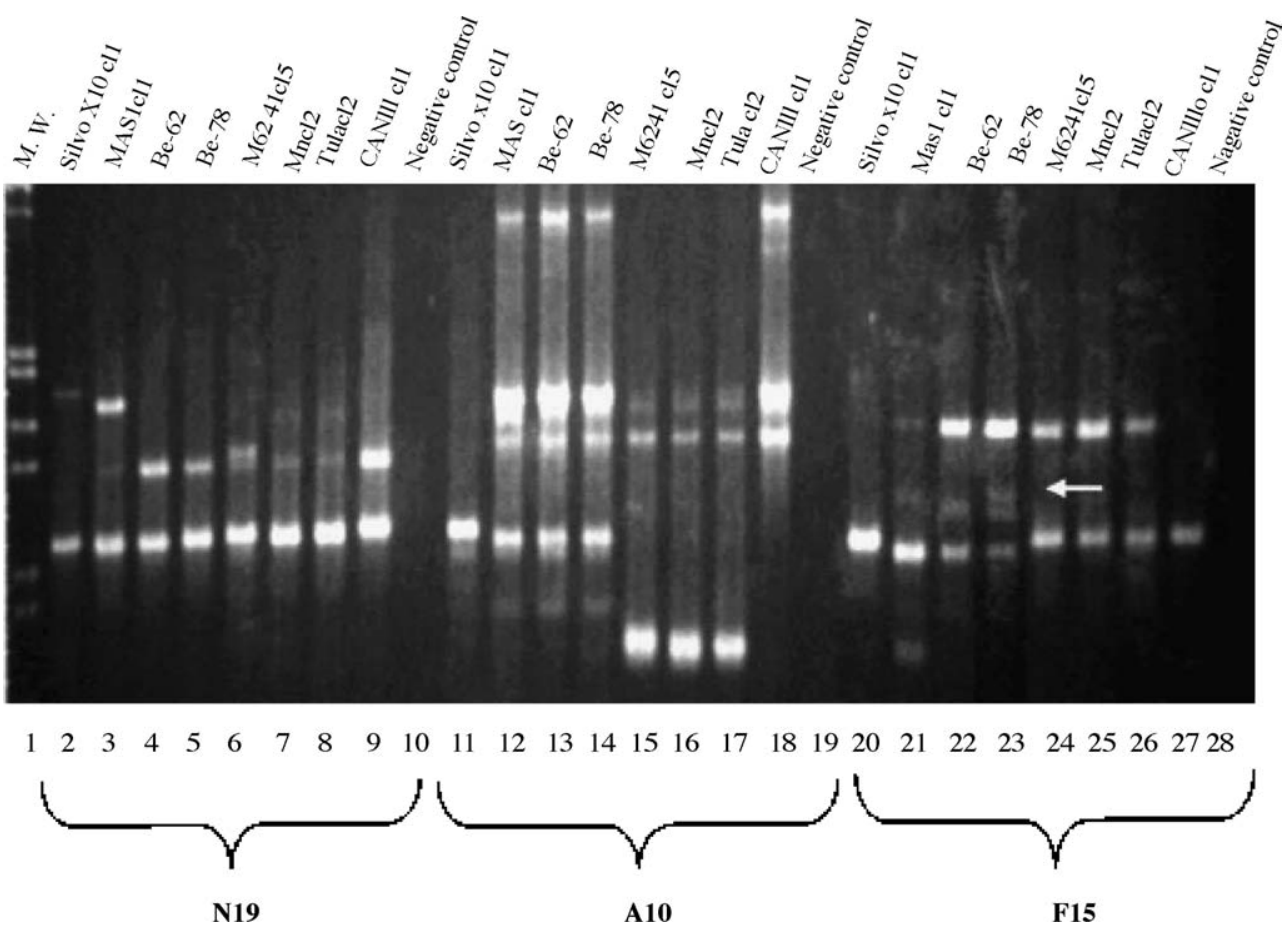

Fig. 2. Representative RAPD patterns of the Be-62 and Be-78 strains and T. cruzi from different genotypes. Lane 1: $1 \mathrm{~kb}$ DNA ladder; lanes 2-10: primer N19; lanes 11-19: primer A10; lanes 20-28: primer F15. For each primer the sequence of the stocks assayed was: SilvioX10cl1 (genotype 19 and 20), MAS1cl1 (genotype 32), Be-62 strain, Be-78 strain, M6241cl5 (genotype 36), MNcl2 (genotype 39), TULAcl2 (genotype 43), CANIIIcl1 (genotype 27) and no DNA template. The white arrow points out the differentiating band between Be-62 strain and Be-78 strain for the primer F15.

primers (F15, N9 and A15) yield products that were different between the two strains. Fig. 2 illustrates one of these differences obtained with the F15 primer. Be62 RAPD profiles differed from MAScl1 profiles in relation to N19, A10, F15, N9, A15 and B19 loci. Be-78 profiles were also different from those of MAScl1 with the same primers, except for A15 (data not completely shown).

Table 2

Alleles (amplicons in pb) detected for the TcAAT-01, TcTAC-02, TcTAT-01, TcAAAT-01, MCLG10, SCLE10 and MCLE01 microsatellites loci in Be-62 of and Be-78 Trypanosoma cruzi strains and their respective clones

\begin{tabular}{|c|c|c|c|c|c|c|c|}
\hline \multirow[t]{2}{*}{ Strains and clones } & \multicolumn{7}{|l|}{ Loci } \\
\hline & TcAAT-01 & TcTAC-02 & TcTAT-01 & TcAAAT-01 & MCLG10 & SCLE10 & MCLE01 \\
\hline Be-62 & 251-259 & $257-259$ & 183-201 & $256-271$ & 175-177 & 273-275 & $257-274$ \\
\hline $\mathrm{Be}-62 \mathrm{cl} 3$ & $251-259$ & $257-259$ & $183-201$ & $256-271$ & $175-177$ & $273-275$ & $257-254$ \\
\hline Be-62cl8 & $251-259$ & $257-259$ & $183-201$ & $256-271$ & $175-177$ & $273-275$ & $257-254$ \\
\hline Be-62cl7 & $251-259$ & $257-259$ & 183-201 & $256-271$ & $175-177$ & $273-275$ & $257-254$ \\
\hline Be-62cl12 & $251-259$ & $257-259$ & $183-201$ & $256-271$ & $175-177$ & $273-275$ & $257-274$ \\
\hline Be-78 & $262-270$ & $262-264$ & 197-207 & 272-275 & 177 & 268 & 149-157 \\
\hline $\mathrm{Be}-78 \mathrm{cl} 2$ & $262-270$ & $262-264$ & $197-207$ & $272-275$ & 177 & 268 & $149-157$ \\
\hline Be-78cl9 & $262-270$ & $262-264$ & $197-207$ & $272-275$ & 177 & 268 & $149-157$ \\
\hline Be-78cl10 & $262-270$ & $262-264$ & 197-207 & $272-275$ & 177 & 268 & $149-157$ \\
\hline Be-78cl15 & $262-270$ & $262-264$ & $197-207$ & $272-275$ & 177 & 268 & $149-157$ \\
\hline
\end{tabular}

Data in bold refer to parental Trypanosoma cruzi strains. 


\subsection{Microsatellite patterns of the parental strains $B e-62$ and Be-78 and their clones}

We profiled the nuclear genome of both parental strains and their respective clones by analyzing seven microsatellite loci (Table 2). For all investigated loci the fluorescent PCR products were different between the strains Be-62 and Be-78. However, the microsatellite profiles of the clones were equivalent to their respective parental strains, indicating that both strains are

\section{SilX10 cl1}

CANIII d1

Be-62

MAS1 cl1

Be-78

M6241 cl 5

MN cl2

TULA cl2

Fig. 3. An unweighted pair-group method with arithmetic averages (UPGMA) dendogram depicting the phylogenetic relationships among Be-62 and Be-78 strains and clones belonging to the principal genetic groups of T. cruzi (Tibayrenc and Ayala, 1988), assayed by isoenzymatic electrophoresis and RAPD. The scale indicates genetic distances estimated with the index of Jaccard (1908). 
probably monoclonal populations. This hypothesis is corroborated by the fact that multi-peak patterns were not observed for the parental strains. We detected only one-peak or two-peak profiles, interpreted as homozygosis and heterozygosis at the specific locus for both Be-62 and Be-78 strains.

\subsection{Phylogenetic analysis}

For the phylogenetic analyses we combined the isoenzyme and RAPD data and constructed an UPGMA dendogram showed in Fig. 3. As expected, Be-62 and Be-78 were much more similar to MAScl1 than all the other reference clones used.

\section{Discussion}

The Be-62 and Be-78 strains, although isolated from the same patient in 1962 and in 1978, respectively (Salgado et al., 1962; Lana and Chiari, 1986), display some important biological and molecular differences (Lana and Chiari, 1986; Lana et al., 1996, 1992; Araújo et al., 2002.). These findings raised questions about the differences in the two populations and their phylogenetic relationship. In addition, we were interested to know whether Berenice patient was infected with a multiclonal T. cruzi population and if we could identify this supposed populations mixture in the two isolated strains. In order to clarify these points we extend the characterization of the Berenice strains and their clones, in the present work, by analyzing 22 enzymatic, 9 RAPD and 7 microsatellite loci.

The comparative isoenzymatic characterization, using the six enzymes previously tested (Lana et al., 1996), and another 16 new systems, showed differences in only two loci: PGM, partially confirming previous results of Lana et al. (1996) and DIA-NADH. The similarity of MDH profile now observed may be consequence of the parasites manipulation in the laboratory by successive blood passage in mice as demonstrated by Carneiro et al., (1991). Both strains were very similar to the MAScl1 clone of T. cruzi, used as reference for the genotype 32 (Tibayrenc and Ayala, 1988).

RAPD data showed slight differences in three out of nine primers. Both strains were also related to the genotype 32 of Tibayrenc and Ayala (1988) corroborating the results described above. The UPGMA dendogram built from the MLEE and RAPD combined data confirmed this notion.

To verify if the two Berenice strains are mono or multiclonal populations, both $T$. cruzi strains were cloned, and their clones comparatively analyzed by the microsatellite technique. Considering the sensitivity of this technique the results obtained also showed differences between the parental strains; however, they suggested that both strains are probably monoclonal populations since each strain and their respective clones showed the same amplification profiles with only one or two peaks in all seven loci tested (Oliveira et al., 1998).

Taking together, our data suggest that although the Be-62 and Be-78 strains were different in several important biological properties these strains are in fact phylogenetically very closely related. Both strains can be considered as belonging to the genetic group 32 of Tibayrenc and Ayala (1988), equivalent to Zymodeme A of Romanha et al. (1979) or Z2 of Miles et al. (1978) or Lineage I of Souto et al. (1996) or T. cruzi II group (Satellite Meeting, Rio de Janeiro, Anon, 1999) which, at least in Brazil, comprises T. cruzi that are predominant in the domestic cycle of the disease.

Finally, although we have confirmed results previously reported (Lana et al., 1996) demonstrating that Be-62 and Be-78 are different populations, we were not able to detect the presence of subpopulations in the two strains with the parameters used here, suggesting that more discriminating and sensitive molecular markers may still be necessary for a better characterization of these strains. These results do not allow us to discard the possibility that the patient Berenice was infected more than once during her life. However, if we admit that Berenice had been infected only once, the host immune system might have played an important role in the modulation of $T$. cruzi population during the long-term infection.

\section{Acknowledgements}

We thank Afonso da Costa Viana, Departamento de Parasitologia, ICB, UFMG, for the precious technical assistance during the cloning of the T. cruzi strains and Dr. Juliana Pimenta, Departamento de Bioquímica e Imunologia, ICB, UFMG, for providing us the primers for the microsatellite analyses. This work 
was supported by Fundação de Amparo à Pesquisa de Minas Gerais (FAPEMIG), Conselho Nacional de Desenvolvimento Científico e Tecnológico (CNPq) and WHO Special Program for Research and Training in Tropical Diseases.

\section{References}

Anon, 1999. International Symposium to Commemorate the 90th Anniversary of the Discovery of Chagas' Disease, Recommendation from Satellite Meeting, Rio de Janeiro, Brazil. Mem. Inst. Oswaldo Cruz 94, 429-432.

Araújo, F.M., Bahia, M.T., Magalhães, N.M., Martins-Filho, O.A., Veloso, V.M., Carneiro, C.M., Tafuri, W.L., Lana, M., 2002. Follow-up of experimental chronic Chagas disease in dogs: use of polymerase chain reaction (PCR) compared with parasitological and serological methods. Acta Trop. 81, 21-31.

Ben Abderrazak, S., Guerrini, F., Mathieu-Daudé, F., Truc, P., Neubauer, K., Lewicka, K., Barnabé, C., Tibayrenc, M., 1993. Isozyme electrophoresis for parasite characterization. In: Hyde, J.E. (Ed.), Methods in Molecular Biology, Protocols in Molecular Parasitology, vol. 21. Humana Press, Totowa, NJ, pp. 361-382.

Brisse, S., Barnabé, C., Tibayrenc, M., 2000. Identification of six Trypanosoma cruzi phylogenetic lineages by random amplified polymorphic DNA and multilocus enzyme electrophoresis. Int. J. Parasitol. 30, 35-44.

Chagas, C., 1909. Nova Tripanomíase humana. Estudos sobre morfologia e o ciclo evolutivo do Schizotrypanum cruzi, n. gen., $\mathrm{n}$. sp., agente etiolójico da nova entidade morbida do homem. Mem. Inst. Oswaldo Cruz 1, 159-218.

Felsenstein, J., 1989. PHYLIP—Phylogeny Inference Package (Version 3.2). Cladistics 5, 164-166.

Gomes, L.M., Araújo, S.M., Chiari, E., 1991. Trypanosoma cruzi: growth of clones on solid medium using culture and blood forms. Mem. Inst. Oswaldo Cruz 86, 131-132.

Hecker, K.H., Roux, K.H., 1996. High and low annealing temperatures increase both specificity and yield in touchdown and step-down PCR. Biotechniques 20, 478-485.

Jaccard, P., 1908. Nouvelles recherches sur la distribution florale. Bull. Soc. Vaudoise Sci. Nat. 44, 223-270.
Kilgour, V., Godfrey, D.G., 1973. Species-characteristic isoenzymes of two aminotransferases in trypanosomes. Nat. New Biol. 244, 69-70.

Lana, M., Chiari, C.A., 1986. Caracterização biológica comparativa das cepas Berenice-62 e Berenice-78 de Trypanosoma cruzi, isoladas da mesma paciente em diferentes períodos. Mem. Inst. Oswaldo Cruz 81, 247-253.

Lana, M., Chiari, C.A., Chiari, E., Morel, C.M., Gonçalves, A.M., Romanha, A.J., 1909. Characterization of two isolates of Trypanosoma cruzi obtained from the patient Berenice, the first human case of Chagas'disease described by Carlos Chagas in 1909. Parasitol. Res. 82, 257-260.

Lana, M., Chiari, E., Tafuri, W.L., 1992. Experimental Chagas' disease in dogs. Mem. Inst. Oswaldo Cruz 87, 59-71.

Miles, M.A., Souza, A., Povoa, M., Shaw, J.J., Lainson, R., Toye, P.J., 1978. Isozymic heterogeneity of Trypanosoma cruzi in the first autochthonous patients with Chagas' disease in Amazonian Brazil. Nature 272, 819-821.

Oliveira, R.P., Broude, N.E., Macedo, A.M., Cantor, C.R., Smith, C.L., Pena, S.D.J., 1998. Probing the genetic population structure of Trypanosoma cruzi with polymorphic microsatellites. Proc. Natl. Acad. Sci. U.S.A. 95, 3776-3780.

Page, R.D., 1996. TreeView: an application to display phylogenetic trees on personal computers. Comput. Appl. Biosci. 12, 357358.

Romanha, A.J., Pereira, A.A.S., Chiari, E., Kilgour, V., 1979. Isoenzyme patterns of cultured Trypanosoma cruzi: changes after prolonged subculture. Comp. Biochem. Physiol. 62B, 139142.

Salgado, J.A., Garcez, P.N., Oliveira, C.A., Galizzi, J., 1962. Revisão clínica atual do primeiro caso humano descrito de Doença de Chagas. Rev. Inst. Med. Trop. São Paulo 4, 330-337.

Sneath, P.H.A., Sokal, R.R., 1973. Numerical classification. In: Kennedy, D., Park, R.B. (Eds.), The Principles and Practice of Numerical Classification. Freeman, San Francisco, pp. 230-234.

Souto, R.P., Fernandes, O., Macedo, A.M., Campbell, D.A., Zingales, B., 1996. DNA markers define two major phylogenetic lineages of Trypanosoma cruzi. Mol. Biochem. Parasitol. 83, $141-152$.

Tibayrenc, M., Ayala, F.J., 1988. Isoenzime variability in Trypanosoma cruzi, the agent of Chagas' disease: genetical, taxonomical, and epidemiological significance. Evolution 42, 277-292. 